\title{
Corrigendum: Tsetse flies should remain in protected areas in KwaZulu-Natal
}

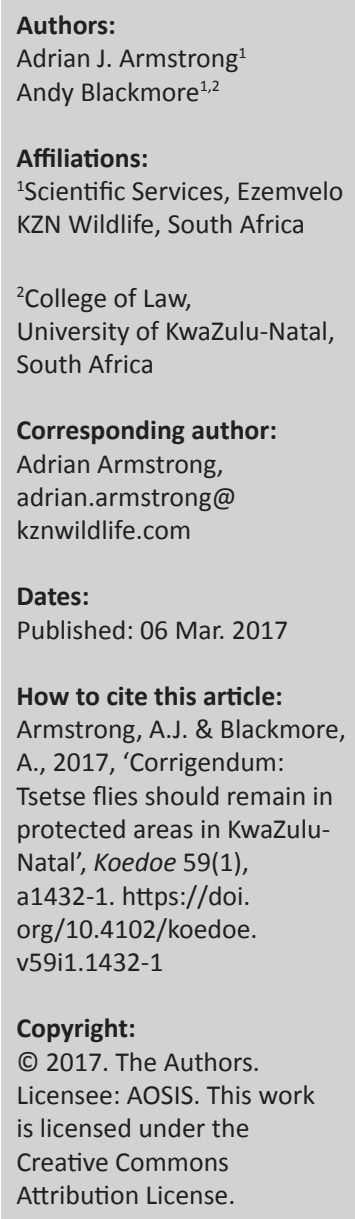

Copyright:

(C) 2017. The Authors. Licensee: AOSIS. This work

is licensed under the

Creative Commons

Attribution License.

In the version of this article initially published, Andy Blackmore's second affiliation was omitted. His second affiliation is the College of Law, University of KwaZulu-Natal, South Africa. The error has been corrected in the PDF version of the article. 